Article

\title{
Beyond Sex/Work: Understanding Work and Identity of Female Sex Workers in South China
}

\author{
Yu Ding \\ Department of Sociology and Social Work, Sun Yat-sen University, 510275 Guangzhou, China; \\ E-Mail: dingyu6@mail.sysu.edu.cn
}

Submitted: 16 November 2019 | Accepted: 25 February 2020 | Published: 28 April 2020

\begin{abstract}
While scholars and activists often advocate using the term 'sex worker' in preference to prostitute, in my research I found that female prostitutes in the Pearl River Delta area, south China, do not like to be addressed as such, and prefer the title xiaojie in Chinese. 'Sex worker' generalises the heterogeneity of meanings these women identify and attribute to what they do; it does not capture the complex cultural meanings involved in the term xiaojie. It is stigmatising in that what is exchanged within the transaction is less defined by sexual acts and more by a diversified range of activities. The women employ what is useful to them and infuse new meanings in it to construct gender images and identities to resist the sex worker stigma and to express their desires as rural-to-urban migrants. Using xiaojie becomes a destigmatising and gender tactic. I also found that the women discard the idea of finding alternative jobs partly because of the practical difficulty, and partly because they do not want to work (gongzuo) any more in the future. This study highlights the importance of exploring desire and agency to understand the lived experiences of this particular group of women.
\end{abstract}

\section{Keywords}

desire; destigmatisation; gender; sex worker; South China

Issue

This article is part of the issue "Left Behind? Women's Status in Contemporary China" edited by Robert Walker (Beijing Normal University, China) and Jane Millar (University of Bath, UK).

(C) 2020 by the author; licensee Cogitatio (Lisbon, Portugal). This article is licensed under a Creative Commons Attribution 4.0 International License (CC BY).

\section{Introduction}

[It] isn't a kind of work....When I have nothing much to do, I go to my friends' to play Mahjong and watch TV, and we play and drink till about ten at night. Then I prepare to go out. It is all up to me whether I go out or not. If I am not happy one day, I'll just stay in or sleep....I don't think a job/work [meaning: gongzuo] is like this. It should have regular income and fixed working time. It's not so free.

This is what Song said when I asked whether she thinks being a xiaojie is a kind of work. Her answer helps us understand what women involved in the sex industry think about work and sex work. Based on the ethnographic research on the perception of Chinese xiaojies regarding work and their lived experience in the Pearl River Delta area, South China, I found that most did not consider 'sex worker' an appropriate title, nor do they want to be called 'prostitutes' or other localised stigmatising titles (such as 'chicken'). Song's narrative is typical among the women I interviewed, showing how most of them resist the idea of sex work and even work in general.

In this article I want to explore (1) how xiaojies understand what they do; (2) how they give meanings to the term sex worker (xing gongzuo zhe) and challenge work as an institution; and (3) how they identify themselves within the social, economic, cultural and political context of the Pearl River Delta area and use these to challenge labelling as women migrants from rural backwardness and sexually dangerous prostitutes.

During my fieldwork I visited various night entertainment sites in the Pearl River Delta, including five nightclubs, four hair salons, four leisure centres and two foot 
massage parlours, and also places famous for street solicitors. I lived with two xiaojies on and off for six months. I established good relations with xiaojies, mamasans, alcohol sellers, drug dealers and users and also gang members. I also got to know people engaged in related activities and occupations including security guards at entertainment sites, landlords of xiaojies, store owners in 'red-light' districts and more, thereby assembling much information about the night entertainment industry, the area, the people and their lifestyles. In addition, formal in-depth and multiple interviews were conducted with 23 xiaojies who were doing different kinds of sexrelated jobs, including street solicitors, call girls, massage girls working at clients' homes, nightclub girls, mamasans who were previously xiaojies, hair salon girls and freelancers (similar to 'second wives' but typically living with different men at the same time while doing other jobs like cleaning). Six of them were married at the time of the interview and three had children.

\section{From Xiaojie to Female 'Sex Worker'}

Xiaojie was a respectable form of address for young and unmarried women born into rich big families in ancient China. The term was dropped at the founding of new China due to its capitalist/feudalist connotations. It was then brought back into use by Hong Kong/Taiwan businesspeople coming to the mainland in the 1980s during the economic reform, when it became a common mode of address for all women in urban areas (similar to the English 'Miss/Ms.'). However, about a decade ago, women who had been quite used to the term $x i$ aojie became very sensitive about how it became a specific form of address for prostitutes, the result of businessmen visiting entertainment sites and using it in this way. Customers in retail shops and restaurants and service providers in these sites use other words such as guniang (girl), xiaomei (literally: little sister) or liangnv (pretty lady) instead of xiaojie to address each other. The Pearl River Delta is said to be the place where the term xiaojie was first used to indicate 'prostitute.' It became so prevalent that even some community offices made new guidelines for their everyday work stating that calling female migrants xiaojie would be an offence. From then on, the ordinary Chinese word xiaojie was not considered ordinary anymore, and the term's ambiguous meaning have provoked many discussions ever since, especially on changes in the Chinese language and the proliferation of prostitution coinciding with the period of economic 'opening up.' It seems that xiaojie has become a cultural code at this particular historical moment, and it brought the prostitution issue to people's attention in a quiet yet permeative manner.

Other than in popular culture, there also seems to be an intellectual tension in grappling with the concepts of prostitution, moral decay, victims and sex workers, as well as in the meanings and associated identities attached to them. Much of this debate stems from Western scholars and activists, yet it has also been influential in scholarly and policy discourse in non-Western societies, including China. At the time when, with the increase of rural-to-urban migration, the notion of xiaojie had taken on a new cultural meaning, Chinese academics become embroiled more deeply in the contradiction of attitudes held by different schools.

The long-standing ideology that prostitution is a product of capitalist exploitation, a social corruption and a stigma of moral decay forms the basis of the moralistic views that criticise prostitute women as lazy, morally degraded and deviant (e.g., Si, 1997; Zhang, 2004). Scholars in this school of thought insist that the institution of prohibition and re-education should be established to control it. At that time, dominant discourses set the tone and direction for research. Jeffreys (2004) criticises these researchers' 'cold war ideology' and political stance, saying that their positivist standpoint and treatment of what they researched as an object rather than as a human subject were methodological biases.

Some scholars began to look at the issue from a different angle, blaming traditional patriarchal culture as the source of prostitution and of women's oppression (e.g., Ding, 1996). Within this framework, discussions are narrowly confined to first-wave feminist ideologies that see prostitute women as victims of male oppression and the patriarchal culture. There is no engagement with the many diverse understandings of prostitution, including the possibility that it might be considered as a form of labour or as an autonomous way in which women may choose to express their agency.

Since the rapid increase of HIV-positive cases in China in the mid-1980s, prostitution has attracted massive academic attention with prostitutes often taken to be part of the floating population that is considered important in HIV/AIDS control (Choi, 2011). Women involved were either seen as sexually promiscuous or as the subjects of medical experiments who needed special education and regulation of their sexual behaviour so that they would not transmit the virus to the 'normal' population (He \& Zheng, 1997).

For Chinese academics, this reconstituting of the nature of the issue provided a way of researching the taboo of prostitution from an angle other than the morallyloaded or legally-focused ones that were often facets of political propaganda (Pan, Huang, \& Liu, 2005). Some scholars began to look into the social and cultural dimensions of sexual behaviour, e.g., how the women feel about love and intimacy, how their lifestyle and work may influence the effectiveness of interventions, and so forth. Rather than engaging in moral blame, medical analyses or sympathetic victimisation, they argue that sex work is a kind of work and that being a female sex worker is a right (e.g., Huang \& Pan, 2003; Pan, Huang, \& Liu, 2005; Pan, Huang et al., 2005). It opened up a new direction for researchers to understand the complex nature of prostitution, fundamentally challenging the mainstream view that treats them as the deviant Other. 


\section{3. 'Sex Worker' or Not: Key Debates in China and Abroad}

Whether prostitution is a kind of work is one of the key debates that runs throughout various feminist schools and across the globe. Associated discussions concern prostitute women's identities and what they do/sell. Recent studies have begun to show the disparate situations in which prostitution occurs and the various forms of 'labour' involved (Hoang, 2015; Kong, 2017; Musto, Jackson, \& Shih, 2015). Prostitution may have both positive and negative effects on the involved women's sense of self, which also relates to social background, individual motivations, work locations and life experiences (Benoit et al., 2018). Sometimes due to the complexity of the term, women involved in prostitution are reluctant to call themselves 'sex workers' (Cheng, 2011; Frank, 2007). Each situation is unique, with its own context, suggestive of the underpinning values and pertaining frameworks that are both deeply rooted and evolving.

Key Chinese scholars on prostitution, Pan Suiming, his group of colleagues and postgraduate students, and Huang Yingying adopt an identity and rights framework and hold that xiaojies are 'sex workers,' just like any other labourers and workers. In their work, they interchangeably use the word xiaojie and 'sex worker' to imply the 'right to labour,' and state that "although the women did not explicitly say 'sex work is a kind of work,' none of them take it as not a kind of work" (Pan, Huang et al., 2005, p. 103). They argue that xiaojies often "talk about their work environment, the market situation, and mamasans' attitude to them," which are "exactly the same things other workers will discuss" (Pan, Huang et al., 2005, p. 103). Huang takes the women's narratives on hard factory work and their later entry into the sex business as a causal relation and argues that sex work is a 'parallel movement in profession' from factory work (Huang \& Pan, 2003), taking it as evidence supporting the idea that the sex business is a kind of work.

My study shows that some xiaojies have never done any factory work before taking up their sex business jobs. As second/third generation migrants, they know well about the notorious factory life and some made up their mind to leave the countryside and go directly into the sex business. Women's initial involvement in the sex business is usually due to more than one factor and so why they want to do it, how they decide to do it, what they think about it, and what they envisage the future to bring become important issues for us to understand. Most of my interviewees say they do not think what they do is a kind of work and many express no intention of working (gongzuo) in the future.

Although I deeply understand and appreciate scholars' efforts in advocating the women's free will, right to labour and agency, I consider this unquestioning adoption of 'sex worker' as problematic (Huang, 2018). Few Chinese scholars have paid attention to the naming issue of prostitution, most taking the label 'sex worker' for granted. Without looking into the women's own perceptions of 'sex work,' what they do and aspire to do in a specific context that is socially, economically, culturally and historically different from the West, our understanding of prostitution is incomplete.

Tsang (2019a, 2019b) has used another framework 'edgework' to describe and analyse the double-sidedness of sex workers' experience, pointing out that they need to weigh possible benefits against certain risks and to make a 'bounded rational choice' with respect to their goals (Tsang, 2018). Her work contributes to our understanding of the complexity of prostitution, especially the mixed feelings of the women towards money and other tangible/intangible benefits yielded by their desires (Tsang, Lowe, Wilkinson, \& Scambler, 2018). For women who voluntarily adopt prostitution in China, poor economic condition is not the only or direct reason (Ding, 2016; Liu, 2011). After entering the sex business their economic condition may not have improved much (Ding \& Ho, 2013). Considering the stigma of prostitution, the alienation created by the job and the possible physical harm, the price they have to pay seems to be too high to justify their choice as a purely economic decision. How should we therefore account for their choices? Tsang's framework redirects the focus of academic discussion that has hitherto been directed to the sex work paradigm by raising issues such as difficulty and predicament. Yet, we need to probe into the women's desires to make sense of their life choices.

\section{Agency and Desire: A New Way to Understand Women's Lived Experiences}

My studies show that the decisions of xiaojies are usually not linear, causal, clear and direct, or taken after careful thought. Not all decisions are based upon rational thinking and weighing upon options. When talking about agency, most studies focus on the conscious planning and strategising aspect, i.e., how people's social location and resources affect their personal choices and experiences. The cognitive aspect of agency relating to the women's initiative, imagination, aspirations and dreams that play an 'intangible' role in their decision making, has not been fully explored (Mahler \& Pessar, 2001). These most-neglected elements are important, without which we cannot fully understand the choices xiaojies make, especially those that seem to be irrational, impulsive or hard to comprehend.

Tsang and $\mathrm{Ho}$ (2007, p. 625) argue that the language of desire creates a subjective space, embracing the spontaneous, non-rational and corporeal aspects of people's daily lives, in which they are able to construct their selves. It includes both explicit/speakable/tangible/material aspects and implicit/secretive/unconscious/sentimental longings that are often neglected in academic discourses. It can help drawing a clearer picture of how xiaojies come to certain decisions and how they construct their selves in a specific context. Confusions, difficulties and 
uncertainties they encounter can be understood more clearly. This is important as much research conducted within the identity framework leaves the everyday, unconscious and trivial aspects untouched (Cameron \& Kulick, 2003). Desire is considered to be a special conceptual site that has the most potential to subvert existing social order and norms (Cameron \& Kulick, 2003, p. 627). Thus, it is not only to be understood in professional/academic/elite discourses that usually fail to represent it fully, but should also be understood as a fluid, every day, multidimensional and transgressive articulatory system (Cameron \& Kulick, 2003, p. 627).

I argue that desire and agency should be integrated into our analytical framework to catch the fluidity and multiplicity of the women's self-identifications and to understand the discursive formation of their lived experience. The 'logic of emotion' (Jankowiak, 2006) should be taken as a supplement to the logic of material, work or identity.

The sex work framework gives priority to social status and political rights, which are not the most relevant in the women's lives under the social condition in China. In an increasingly diversified sex market, it is important that we understand how xiaojies, bearing strong stigma without any resources, utilise different aspects of their lives to construct multiple identities in different life stages and contexts to maximise their power and freedom. They present many different gender images, and the mixed and fragmented moments deconstruct the simple identity of 'sex worker' and reveal numerous processes of becoming and identification. My studies show that these women's agency is constituted by, and expressed in, their self-identification, self-practices and in various life skills (Ding, 2017; Ding \& Ho, 2013). These different modes of agency are both a result of structural constraints and a force that is breaking through.

\section{The Changing Ideology of Work}

After the founding of new China, the idea of work was closely linked with the nation's ambition of industrialisation and the political agenda of socialist construction. To work (gongzuo) in a work unit (danwei) was considered a source of pride for the individual. Thus 'work' has a very specific meaning in contemporary Chinese, emphasising paid labour in a recognised profession. It has to be differentiated from dagong, which indicates an emergence of capitalist labour employment relations outside the state sector.

In recent years, self-employment, informal employment and temporary employment such as running a 'WeChat' business (wei shang), webcast, running errands for different employers or doing construction work and earning a daily wage, among others, with less stable income but flexible working venue and time, have become more accepted and even popular, especially among younger generations who are familiar with the internet. Xiaojies' idea of work and future aspirations are similar to these young people. Flexibility, freedom and harm-reduction are now their priorities after seeing China's three generations of migrant workers suffer from sweatshop factory work, low pay without recognition, hazardous working conditions, inhuman regulations, heavy workload and lack of dignity. Lifestyles that support these ideals go beyond personal choice for pleasure and comfort and become a resistance against impairment of individual worth and subjection by mainstream ideology.

From this perspective, Wang (2004), among the very few scholars who have discussed the 'naming' issue of prostitution in China, argues that 'sex work' is not proper and suggests that we consider a new name that can catch the multiple layers of meanings involved in prostitution and also blur the gender boundaries.

\section{Xiaojies' Perceptions of What They Do}

In order to explore xiaojies' perceptions of work and their current jobs, I categorise the women interviewees into four groups according to their different responses to the question: What do you think about what you do?

\subsection{Playing}

Thirteen of the 23 women interviewed either explicitly claim or imply that they are leading a 'playful' life. They give the word 'play' at least three meanings. First, it refers to the 'playful' and entertaining aspects of their jobs and daily lives, such as singing, dancing, playing dice, drinking, chatting, taking drugs, hanging out with friends, etc., as well as flexible 'working' time. Second, it denotes the 'performative' nature of xiaojies' interactions with clients.

I first met $Y Y$ in a Shenzhen nightclub with a male friend of mine. She was dressed in a light-coloured shortsleeved blouse and black trousers, wearing a necklace and a pearl hairpin in her long straight hair. She did not look like other xiaojies who were in tube-tops and miniskirts. I found that the way she talked to me differed very much from how she talked to my male friend. For example, we talked a lot about skincare, hair styles, fashion and boyfriends, but when she turned to my friend, she used a lot of flirtatious language with sexual implications. The whole conversation went on with YY's constant shifting from a 'bestie' of mine to a 'sexy lover' of my friend. She never admitted that she provides sexual services before my friend in order to maintain a 'pure' and 'innocent' image but, when we went to the restroom together, she explained to another xiaojie that her period was late and discussed the possibility of pregnancy.

She told me during our second meet-up two weeks later that she sometimes felt like an actress:

I know what they want and then I swiftly change my tones and how I behave....Sometimes the managers joke about my readiness to change, and I say, yes, I am 
just playing! This is not like a proper job, so what does it matter!

The third meaning attached to a 'playful' life is the transitional and unfixed state of being that xiaojies' experience as rural-to-urban migrants with no clear idea of what to do in the (near) future. When I asked Hong whether she thinks being a xiaojie is a kind of work she said:

How can this be a kind of work?! I don't know even what I am doing. I am just idling my time away....This is not work, just play. I won't treat it as work. Let alone sex work.

She uses 'play' to release herself from the pressure of seeking a definite direction of where she wants to go. Saying that she is 'playing' temporarily saves her from the confusion of being a migrant woman who has not achieved more with the resources she currently has. It also rationalises their 'aimless' lives overwriting the unhappiness they encounter in the job, weakening the 'work' ethic, lightening workload, responsibilities and even the stigma of prostitution.

\subsection{Doing Business}

Some women refer to themselves as businesswomen. The title implies the ability to negotiate, balance and plan that requires vision and competence. They think that it is a better form of address than 'sex worker' since it creates a sense of being urban and modern, an image of sophistication and success, and a sense of security in being able to make their own decisions.

Haibin is very confident, describing herself as a "born businesswoman" having "business acumen at a young age." Her family runs a small shop that has taught her much about maximising profits with limited resources. When she talked about how she decided to be a xiaojie she said:

Everything has its own value. I see not much difference between my insurance job, model job and being a xiaojie, in terms of building client networks. Just that...the latter two need more business acumen and self-motivation....Being a xiaojie is a kind of business that needs input in appearance and interpersonal skills. You need to learn these things before you can earn money and establish relations.

Women working in nightclubs may have a stronger sense of doing business since there has always been a unique connection between businessmen, corrupt government officials and women-centred entertainment (see also Osburg, 2013; Uretsky, 2008; Zurndorfer, 2016). Xiaojies may establish personal networks with these men and learn to make good use of them for personal benefit. Mei showed me a pile of perhaps 100 name cards she had received from clients and other sources. She would call some of them regularly to keep contact. She comments:

Business manager, to be honest, is a good description of my job as a xiaojie. It's not work. It's all about business, establishing relations and building mutual interests. Sometimes I don't think it's easy to be a xiaojie because it needs courage and vision.

It seems unlikely that Haibin and Mei would have been able to attain the same extensive social networks, raised self-esteem and sense of involvement through work in a factory or as a cleaner, waitress or domestic helper.

\subsection{Chulai}

Some women used the Chinese word chulai, literally 'came out,' to describe their ambiguous, dynamic, changing and unfixed condition. Chulai has four layers of meaning to it. First, and most obviously, it refers to the geographical movement from rural village to the city. Secondly, it means moving away culturally from rural 'backwardness' to urban 'advancement,' just as Lan describes it: "The feeling is really like coming out from a closed house." Most interviewees mentioned 'urban,' 'open' and 'modern' when they described their city life. Urban symbols like high street shops, gyms and supermarkets help in acquiring urban knowledge and values (Ding, 2017). For married xiaojies, it also means stepping out from marriage to a new personal space. When they realised that they may not have a more certain future and enjoyable life through marriage, they decided to "find something to do in cities" to obtain a sense of security for themselves. According to Wen, "this 'something' was not necessarily a kind of work," as it was "more like an 'add-on"' to what she had. The fourth connotation of chulai, rare but interesting, as in one xiaojie's narratives, means having overseas exposure.

This group of women find in their unsettled existence a means of expressing their desire to break away from under-developed, static rural environments and become modern, urban and open. The ambiguity of the terms chulai, zuoshi (to do something), zuo (do), or chuqu (going out) destigmatises their status and provides space for them to articulate their choices, especially at a transitional stage in their lives. Migration and being xiaojies are perceived to be just temporary choices where the fixed and stigmatised identity of 'sex worker' is not applicable.

\subsection{Work}

Juan is the only woman among my informants who takes being xiaojie as a kind of work. She has a 4-year-old daughter who was born to a client. As a single mother she has a clear goal of earning money and providing the best she can for her daughter. She firmly believes that:

It is work, with or without regulation.... I depend on this work to raise my daughter. The clients pay us be- 
cause we give out our labour. So, I earn this money for a reason.

She thinks that every form of labour is work, "even grocery shopping is a kind of work." However, she does not think that xiaojies should be called 'sex workers' for it sounds "too deliberate."

\section{Why 'Sex Work' Doesn't Work: Beyond 'Sex' and 'Work'}

\subsection{Neither Sex nor Work}

Twelve out of the other 22 interviewees, like Juan, said the term 'sex worker' only focuses on the aspect of 'sex.' In the increasingly diversified and highly developed sex market in the area, what xiaojies have to offer is far more than just sex. They need to incorporate different aspects of their personal capabilities and create different gender images to tailor to the clients' needs. From the 'work' aspect of the term, the reason why most xiaojies preferred not to be called 'sex workers' are fourfold. First, it cannot guarantee a stable income. This is especially true for street solicitors. Secondly, some feel that they have little dignity in the job. They have to deliberately create a sense of belonging and pride in themselves, which prostitution does not offer as naturally as other jobs do. Thirdly, xiaojies may find no sense of responsibility attached to the job. Hui compared her massage job with her former job as a salesperson. She said the latter "would impose pressure" on her; if she could not "sell that much" in order to meet the basic salary, she would blame herself as a drag on all others. The massage job brought no such feeling because any problems that occurred seemed to her to be "more of an operational or managerial problem of the boss" that had nothing to do with her. She said it was the sense of responsibility of work that brings a sense of fulfilment, which would make one feel better about oneself. Fourthly, xiaojies tend to associate work with the idea of life goals. They consider that a proper job should give a sense of direction in life providing stability, fulfilment and personal growth whereas being a xiaojie does not achieve this.

\subsection{Future Aspiration: Beyond the Work Paradigm}

Twenty-one women among the interviewees showed little interest in finding 'proper' and stable jobs (zhao gongzuo or dagong), such as working in factories, as a domestic helper, a waitress and in sales. Under heavy regulation, migrant workers are 'stuck' in a space between their own lives and modern China, neither attached to the traditional rural values nor able to fully embrace the fruit of development. As rural migrant 'workers' at the lower end of urban employment, they can only be docile bodies and disposable labourers and are deprived of the opportunities to enjoy modern lifestyles and citizenship-and, more importantly, a space of their own where they can explore what they want. It is hard for them to find good and decent jobs which they imagined doing, such as working in companies and being 'white collars' due to their lack of education and skills. Their desire to be sexual, urban and modern subjects cannot be fulfilled under the current employment regimen.

Trying some 'unusual' way outside the work paradigm becomes acceptable, especially in a social environment that promotes self-support and entrepreneurship. The network and experience accumulated by being a xiaojie creates images of being independent, smart and competent, equipping them with strength and courage to face endless challenges. Being a xiaojie thus becomes an alternative outside the 'work' paradigm. They feel a need to make good use of their youth and body and earn themselves a chance to catch up with the fast-changing world as desiring subjects. They are doing what they think to be right at the moment and right for themselves, by breaking away from confinements and taking the risks they think are needed for a better life. What they want is to be seen firstly as people, not as any type of institutionally confined workers (Cheng, 2007, p. 247). Interviewee Hong said that "any deliberate fighting [duikang] is unnecessary." This to some degree shows that work and identity are not what the women care about the most. Instead, they want to anchor themselves in city lives, grasp the chance to transform themselves into urban, modern and sexual subjects. Their refusal of the 'sex worker' label demonstrates their refusal to accept a fixed identity at this transitional stage. And their refusal of, and confusion over, the word 'work' is a challenge not only to the label 'sex work' as perceived in academic debate, but also to the work paradigm as a whole.

\section{Xiaojie as Destigmatising and Gender Tactics}

The term 'sex worker' emphasises only the most tabooed aspect of the job, as if what the women sell in exchange for money is just their body and sex. It resembles a negative Chinese term for prostitution-maiyin (selling eroticism)-which strongly emphasises the 'sex/flesh' aspect that is condemned by both the deeply rooted Confucian culture and socialist morality. With their multiplicity of roles/images, the women do not want to be defined merely as 'sex' workers. The term xiaojie is ambiguous and does not have a fixed institutional definition of the person to whom it can be applied. The women can appropriate titles and addresses that are useful and proper in different settings to weaken the prostitution stigma.

\subsection{Xiaojie as Urban Signifier}

Xiaojies want to embrace an urban way of life to weaken the rural stereotype imposed on them and to raise their self-esteem. They had imagined city life before migration, as indicated in different ways in their narratives, e.g., in their complaints of rural poverty, longing for pretty clothes, dreams of candies, the giving-up of schooling, 
wishes to work in the cities and more (Ding, 2011). The imaginary operates as a mode of agency. They do not want to stay in rural villages where they cannot share the national economic progress, especially as the unfairness perceived is highly gendered. Their strong desire to be urban makes them willing to take risks rather than to pursue factory life, which is usually considered more normal and stable. Their wish is to anchor themselves in urban space, to participate in the fast-paced urban life and to find themselves places in the Chinese economic transition to a post-socialist state. As different women express:

No matter how, I feel happy right now. I earn my own money, enjoying a different life here. My time is flexible.... can't go back to rural life. (Juan)

We don't want to farm anymore. Farming has no future. We must go out and see how people are living their lives in the cities. We are different from our parents' or grandparents' generations because we have the chance to see more. (Lan)

Xiaojie, with its specific urban connotation, gives them space to evade the image of being rural, passive and weak and to express urban dreams. They may package themselves as smart businesswomen or internationally experienced xiaojies to create a gender image that incorporates urbanity, sophistication and competence and which counteracts the image often imposed on them in both the popular media and academia.

\subsection{Xiaojie as Young and Virginal}

Historically the term xiaojie was associated with youthfulness, being unmarried and virginity. Even now in our everyday language, it is used mostly to address young women in urban settings. From their migration and urban living experience, the women have come to new understandings of youth-a good time to try new things, face the reality of the enlarging rural-urban gap and explore new lifestyles. Youth is also perceived as connoting important traits of a modern woman, including the awareness and skills to maintain bodily and emotional activeness and youthfulness. The women utilise the term's underlying meanings instead of 'sex worker,' which says nothing about women's gender, age or femininity, in order to express their desires for an 'eternal youthfulness' and a fresh new life out of rural poverty and marriage.

They can be 'playful' wives who enjoy sexual freedom and pleasure and take pride in their sexual skills without concern of being regarded as promiscuous. They gain more knowledge on love and intimacy and build up their experience and confidence to resist the existing gender/sexual stereotypes that women should marry early, be subdued and faithful, care for their children, be passive in sex, be monogamous, etc. They endure the difficulty encountered in keeping up with the pace of urban life but, in so doing, increase their social and sex- ual knowledge and life perspectives. At the same time, they turn their rural past into a kind of quality that shows perseverance, adaptability and a willingness to engage in hard work. Together with their youthfulness, they become healthy, strong, flexible women who combine urbanity and rural 'purity.'

\subsection{Xiaojie as Modern Connotation}

The women interviewed project their desires to be open, flexible, independent, sophisticated, onto the term xiaojie and create new meanings for it. By being xiaojies, either according to its literal meaning or as an occupation, they hope to acquire modern women's sexual autonomy and the ability to utilise their sex and body, often their only capital and resources, to gain more control of life. They also hope to have more social exposure, a greater personal space and better prospects. These hopes are reflected in many of their decisions, such as to migrate, enter the sex business and to have extra-marital relationships; and also, in their perceptions of work, marriage, intimate relations, opportunity and challenges. They try to make the best out of their adverse situations and negotiate gender images to present a femininity that is associated with autonomy, openness and flexibility. They understand these as the character and core values of modern women-not being confined in a static and limited space, not being satisfied with what one already has, not to be bounded by rural and gender kinship norms, but to be competent and to live in one's own way.

\section{Conclusion}

This article is a reflection on, and critique of, the tendency of academics and activists to characterise Chinese prostitute women as 'sex workers.' In everyday life, xiaojies experience repeated discrimination not only because they are labelled as immoral and illegal prostitutes, but also because they are considered to be promiscuous and bad women, as well as being backwards, coarse and uncultured rural migrants. They utilise destigmatising and gender tactics not only to weaken these stereotypes but also to break away from existing gender and moral standards and refashion themselves as sexy, open, urban, modern and capable women. 'Sex worker' is too homogeneous and overarching a term to be able to adequately represent all these factors. It fails also to reflect xiaojies' perception of work, while its use may even prejudice some of their desires and aspirations to be modern, urban and sexual subjects.

Academic discussions on the nature of prostitution and the labels should not focus solely on work identity but should also embrace consideration of the desires and multifaceted aspirations of women engaging in prostitution and recognise how their perceived identities differ in various contexts. It is difficult for women engaged in prostitution to imagine substantial improvements in their livelihood arising from institutional reform (such as po- 
litical recognition of prostitution as a legal form of work, or acknowledgement of workers' rights) without fundamental change to the household registration (hukou) system and to the many related regulations that effectively discriminate against the working class. They do not attempt to improve their situations via any form of political efforts. Their self-identification as xiaojies rather than sex workers, and apparent lack of interest in discourses on sex workers' rights, may reflect their anti-institutional sentiments - a resistance against the institutional ascription of class and gender roles for migrant women. By reviewing key Chinese literature on prostitution situated in a global trend, I argue that it is important to explore the desires and aspirations that have motivated these women to go beyond multiple boundaries-beyond their place of origin, social roles, gender normativity, traditional work ethics, proper femininity, etc., to become migrants and xiaojies.

The term xiaojie is imperfect because it is already stigmatised. But its ambiguity gives space for women practising prostitution to transform, to become, and most of all, to struggle against people's negative impressions of this marginal lifestyle, albeit the space available to them is heavily constrained by China's legal, moral and cultural regulation of prostitution. As migrants, the women are leading drifting lives, and are always on the move. Confusion and uncertainty characterise many of their experiences in their pursuit of modern gender subjectivity. I argue that it is important to consider these experiences, desires, aspirations and actions to be modes of agency and destigmatising tactics, rather than as a manifestation of weakness. The women are willing to take risks, transgress boundaries and explore new ways in order to seek a way out of their predicament. What they think and have done may seem to be trivial, unnecessary and unworthy to most of us, but the women nevertheless use their agency to create opportunities for exploration and becoming. It is through little positive resources that women account for why they have deviated from the dominant cultural storyline, while maintaining an image of self-worth. They may not be able to achieve the kind of success that they want because of the limited resources they have and the unfavourable circumstances they are in, but their efforts as individuals should be recognised as expressing their desires for a better life and a refusal to be excluded from the process of modernisation.

My argument against 'sex worker' is not just based on some xiaojies' personal preference or individual standpoint, but for the purpose of reaching a deeper understanding of the women's daily lives, and their micro resistance to existing gender relations, gender stereotypes and social discrimination. My views of reconsidering the appropriateness of 'sex work' is an entry point into a bigger reflection of how we want to address women's rights and social position, and what is a more pragmatic approach of reaching the goal.

This research shows the importance of identifying the gap between academic/activist viewpoints and the women's own experiences and voices. The language of desire is employed to understand their lived experience. In the women's everyday lives we can see another kind of power that is micro/mundane, yet subversive.

\section{Acknowledgments}

I want to thank all the interviewees and people involved in this study for the kind sharing of their knowledge in this field and great patience with me. They have said what they know and what they thought, and I thank them for just being themselves. I also want to express my gratitude to the reviewers for their comments and suggestions, which helped improving this article a lot. My last but not least thanks go to the editors for their great work. They offered constant support and advice throughout the preparation of this article, which I am really indebted to. This article is a partial fulfillment of the research project "Women's Social Work Practice with a Structural Social Work Perspective and Gender Sensitivity" supported by the National Social Science Fund of China (project number 17BSH143).

\section{Conflict of Interests}

The author declares no conflict of interests.

\section{References}

Benoit, C., Smith, M., Jansson, M., Magnus, S., Flagg, J., \& Maurice, R. (2018). Sex work and three dimensions of self-esteem: Self-worth, authenticity and selfefficacy. Culture, Health \& Sexuality, 20(1), 69-83.

Cameron, D., \& Kulick, D. (2003). Introduction: Language and desire in theory and practice. Language \& Communication, 23, 93-105.

Cheng, S. (2007). Romancing the club: Love dynamics between Filipina entertainers and GIs in U.S. military camp towns in South Korea. In M. B. Padilla, J. S. Hirsch, M. L. Miguel, R. E. Sember, \& R. G. Parker (Eds.), Love and globalization: Transformation of intimacy in the contemporary world (pp. 226-251). Nashville, TN: Vanderbilt University Press.

Cheng, S. (2011). Sexual protection, citizenship and nationhood: Prostituted women and migrant wives in South Korea. Journal of Ethnic and Migration Studies, 37(10), 1627-1648.

Choi, S. Y. P. (2011). State control, female prostitution and HIV prevention in China. The China Quarterly, 205, 96-114.

Ding, J. (1996). A case study on female prostitutes, sexual exploitation and violence. Beijing: China.

Ding, Y. (2011). Everyday lives and self practices of ruralto-urban migrant female sex workers in the Pearl River Delta area. South China Population, 26(5), 43-51.

Ding, Y. (2016). Desires: Transitions and new possibilities of sex work in the Pearl River Delta area. Beijing: Social Sciences Academic Press. 
Ding, Y. (2017). Eating the rice bowl of youth: Xiaojies' everyday self practices as doing citizenship from the margins. Citizenship Studies, 21(7), 842-859.

Ding, Y., \& Ho, P. S. Y. (2013). Sex work in China's Pearl River Delta: Accumulating sexual capital as a lifeadvancement strategy. Sexualities, 16(1), 43-60.

Frank, K. (2007). Thinking critically about strip club research. Sexualities, 10(4), 501-517.

He, Q. Y., \& Zheng, D. Z. (1997). An analysis of the effectiveness of HIV/AIDS education among xiaojies. China Journal of STD/AIDS Prevention and Control, 3(5), 208-211.

Hoang, K. K. (2015). Dealing in desire: Asian ascendancy, western decline, and the hidden currencies of global sex work. Berkeley, CA: University of California Press.

Huang, Y. Y. (2018). Sexuality, body and sociology of story-telling. Beijing: Social Sciences Academic Press.

Huang, Y. Y., \& Pan, S. M. (2003). Female sex workers in the labour market in north China. Sociological Studies, 3, 51-63.

Jankowiak, W. (2006). Gender, power, and the denial of intimacy in Chinese studies and beyond. Reviews in Anthropology, 35(4), 305-323.

Jeffreys, E. (2004). China, sex and prostitution. London: Routledge Curzon.

Kong, T. S. K. (2017). Sex and work on the move: Money boys in post-socialist China. Urban Studies, 54(3), 678-694.

Liu, M. (2011). Migration, prostitution, and human trafficking: The voice of Chinese women. New Brunswick: Transaction Publishers.

Mahler, S. J., \& Pessar, P. R. (2001). Gendered geographies of power: Analyzing gender across transnational spaces. Identities, 7(4), 441-459.

Musto, J., Jackson, C. A., \& Shih, E. (2015). Prostitution and sex work. In J. D. Wright (Ed.), International encyclopedia of social and behavioral sciences (2nd ed., Vol. 19, pp. 279-285). Oxford: Elsevier.

Osburg, J. (2013). Anxious wealth: Money and morality among China's new rich. Stanford, CA: Stanford University Press.
Pan, S. M., Huang, Y. Y., \& Liu, Z. Y. (2005). Situation and inspiration: Study on three red-light districts in southwest China. Kao Hsiong: Universal Press.

Pan, S. M., Huang, Y. Y., Wang, J., Zhang, H. X., Yang, R., He, W., . . Zhang, C. M. (2005). Female sex workers: The rights of labour. Hong Kong: Dadao Press.

$\mathrm{Si}, \mathrm{Q}$. S. (1997). The macro policies of prostitution prohibition. Journal of Jiangsu Police Officer College, 1, 34-37.

Tsang, A. K. T., \& Ho, P. S. Y. (2007). Lost in translation: Sex and sexuality in elite discourse and everyday language. Sexualities, 10(5), 623-644.

Tsang, E. Y. H. (2018). Finding hope as a 'tempting girl' in China: Sex work, indentured mobility, and cosmopolitan individuals. Deviant Behavior, 39(7), 896-909.

Tsang, E. Y. H. (2019a). China's commercial sexscapes: Rethinking intimacy, masculinity and criminal justice. Toronto: University of Toronto Press.

Tsang, E. Y. H. (2019b). Selling sex as an edgework: Risk taking and thrills in China's commercial sex industry. International Journal of Offender Therapy \& Comparative Criminology, 63(8), 1306-1329.

Tsang, E. Y. H., Lowe, J., Wilkinson, J. S., \& Scambler, G. (2018). Peasant sex workers in metropolitan China and the pivotal concept of money. Asian Journal of Social Science, 46(3), 359-380.

Uretsky, E. (2008). 'Mobile men with money': The sociocultural and politico-economic context of 'high risk' behaviour among wealthy businessmen and government officials in urban China. Culture, Health, and Sexuality, 10(8), 801-814.

Wang, J. L. (2004). Commercial sex services/consumption: A new naming. Zhejiang Academic Journal, 4, 202-211.

Zhang, Y. H. (2004). The causes of the formation, essence and harm of the current hedonism. Journal of Shanxi Normal University (Social Science Edition), 1, 18-23.

Zurndorfer, H. T. (2016). Men, women, money, and morality: The development of China's sexual economy. Feminist Economics, 22(2), 1-23.

\section{About the Author}

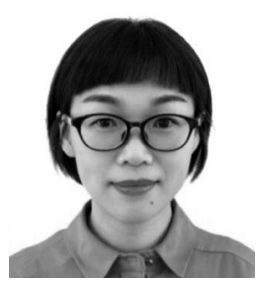

Yu Ding is an Associate Professor in the Department of Sociology and Social Work at the Sun Yat-sen University in Guangzhou, China. She has conducted several years of fieldwork on female sex workers and night entertainment in the Pearl River Delta area, South China, and has several publications on this topic in both English and Chinese. Her research interests include women's everyday lives, marriage and family and social work service provision for women. 